\title{
Modalidades espectrales: vínculos entre la justicia y el derecho en la filosofía derridiana ${ }^{l}$
}

\section{Spectral modalities: Links between justice and law in Derridean philosophy}

\author{
GABRIELA BALCARCE \\ Unversidad de Buenos Aires (Argentina)
}

Recibido: 17-12-2007 Aprobado definitivamente: 12-11-2008

\begin{abstract}
RESUMEN
El siguiente artículo intenta pensar un modo de articulación de la relación aporética entre la justicia y el derecho presentadas por la filosofía derridiana de los últimos años, bajo la exigencia de pensar una justicia que posea el carácter de la incondicionalidad, una justicia irreductible al derecho. A nuestro juicio, el énfasis del filósofo franco-argelino por establecer tal distinción
\end{abstract}

1 El presente artículo ha sido elaborado sobre la base de mi tesis de licenciatura en Filosofía por la Universidad de Buenos Aires bajo la dirección de la Dra. Mónica B. Cragnolini. Le agradezco especialmente su dirección en los estudios derridianos, sin la cual dicho trabajo no hubiera sido posible, así como también a todas las personas y/o instancias que posibilitaron de una manera u otra la escritura de estas reflexiones. En particular, al proyecto de investigación PIP Conicet «La impronta nietzscheana en los debates éticos en torno a la comunidad» (PIP ${ }^{\circ}$ 5854 del Conicet. Directora: Dra. Mónica Cragnolini. Lugar de trabajo: Instituto de Filosofía Dr. Alejandro Korn, Facultad de Filosofía y Letras. Periodo: 2004-2007); al grupo de discusión «Violencia y política: la constitución de la subjetividad frente a la dominación» (Director: Lic. Mario M. Gómez, Co-director: Lic. Bernardo Ainbinder. Facultad de Filosofía y Letras, Universidad de Buenos Aires. Res. CD 1377/07. Periodo: 2007-2008). Mis agradecimientos también a mi querida colega, la Prof. Virginia Ketzelman por sus bastos conocimientos del inglés que permitieron la mejor traducción del asbtract de este artículo. 
concluye en un hiato problemático, en la medida en que dicho concepto quedaría relegado al estatuto de la trascendencia, cuando no al de una idea regulativa en el sentido kantiano del término. Para evitar este hiato, propondremos un posible vínculo entre el derecho y la justicia entendido como una forma de contacto entre lo posible y lo imposible. Para ello, nos valdremos de la categoría de espectro y de la modalidad de existencia que esta figura presenta, a saber, la del asedio.

\author{
PALABRAS CLAVE \\ JUSTICIA, DERECHO, ESPECTRO, ASEDIO
}

\begin{abstract}
The following article attempts to find a way of articulating the aporethic relationship between justice and law presented by Derridean philosophy in the last years, where justice must be regarded as bearing the character of unconditionality and being therefore irreducible to law. To our minds, the French-Algerian philosopher's emphasis on substantiating such distinction reaches a problematic hiatus, insofar as such concept of justice would be relegated to the statute of transcendence, if not to the extent of a regulative idea in the Kantian sense of the term. In order to avoid this hiatus, we propose a possible link between law and justice being it understood as a form of contact between the possible and the impossible, and we use both the category of spectre and its modality of existence, i.e., haunt.
\end{abstract}

\title{
KEY WORDS
}

JUSTICE, LAW, SPECTRE, HAUNT

Si me dispongo a hablar extensamente de fantasmas [...] es en nombre de la justicia.

Derrida, Spectres de Marx, p. 15

I.1. LA CUESTIÓN DE LA JUSTICIA RESUlTA CENTRAL para poder elucidar el ámbito ético-político de la reflexión derridiana. Desde la publicación de Fuerza de ley. El fundamento místico de la autoridad, ${ }^{2}$ una obra que surge a partir de un coloquio en la Cardozo Law School en octubre de 1989 bajo el título Deconstruction and the posibility of justice, pero también en conferencias y entrevistas sucesivas, ${ }^{3}$ dicha temática fue cobrando una importancia capital en el pensamiento derridiano.

Consagrado especialmente a un público del ámbito de lo jurídico, Derrida dedica sus palabras a la idea de justicia y a su relación con el derecho. Dos caminos cercanos delimitan la temática trabajada allí: en primer lugar, frente

2 J. Derrida 1993. Versión castellana: 1995.

3 Cf. J. Derrida 1994a, 1994b, 1998 y 1991. También en algunos pasajes J. Derrida 2004 y en algunos capítulos de J. Derrida y E. Roudinesco 2001. 
a una definición de justicia infinita o incondicionada, la pregunta acerca de si existe la posibilidad de realización de la misma por parte del derecho. En segundo lugar, la problemática de la decisión y de la posibilidad o pertinencia de esperar una decisión justa. Ambos caminos son desarrollados a lo largo de dicha conferencia como el despliegue de dos aporías fundamentales: la aporía de la irreductibilidad de la justicia a cualquier forma de derecho y la imposibilidad de hablar de una decisión justa, habiendo previamente deconstruido el espacio de la decisión entendida como el producto de una deliberación subjetiva autónoma. En este trabajo analizaremos fundamentalmente la primera aporía señalada, a saber, la relación entre justicia y derecho.

Retomando los desarrollos benjaminianos en torno a la cuestión del derecho como monopolio de la fuerza (contenidos en por ejemplo, Para una crítica a la violencia,${ }^{4}$ texto que Derrida analiza profundamente en una obra que secunda la edición de este libro ${ }^{5}$ ), caracteriza al Derecho como «una fuerza autorizada», defendiendo entonces la tesis de que «no hay derecho sin fuerza»: ${ }^{7}$

[L]a aplicabilidad, la enforceability no es una posibilidad exterior o secundaria que vendría a añadirse, o no, suplementariamente, al derecho. Es la fuerza esencialmente implicada en el concepto mismo de la justicia como derecho [luego Derrida rehusará hablar de este tipo de justicia, dejando dicho término sólo para la justicia que no se reduce al derecho], la justicia en tanto que se convierte en derecho. ${ }^{8}$

Aun cuando una ley pueda no ser aplicada, no obstante, la posibilidad de su aplicación (Derrida juega aquí con el verbo «to enforce the law») es una determinación a priori de la ley misma. De manera que la cuestión de la fuerza es inescindible de la cuestión del derecho: en tanto hay derecho, hay fuerza, porque el derecho sólo se sostiene en su aplicabilidad.

Vemos entonces, en primer lugar, que Derrida caracteriza al derecho como fuerza, o al menos como inescindible de ella, en tanto la posibilidad de su aplicación se juega en este ejercicio de fuerza que resulta un ejercicio de conservación del derecho. Esta temática reaparece en El nombre de pila de Benjamin, donde el filósofo francés remite la conservación del derecho a la paradoja de la iterabilidad: siendo el derecho una fuerza que se instala y luego debe conservarse, no sería preciso pensar que la violencia que funda el derecho no es la misma que la que lo conserva, antes bien, es la misma violencia en el juego mismo de

\footnotetext{
4 W. Benjamin 1972.

5 J. Derrida, «Le prénom de Benjamin» en J. Derrida 1994d.

6 J. Derrida 1994d, p. 17 (trad., p. 15).

7 Ibid.

8 J. Derrida 1994d, p. 17 (trad., pp. 15-16).
} 
su iteración que, en un doble movimiento, conserva el derecho reactualizando su origen mismo. En este sentido, Derrida resalta la ambigüedad -por su doble acepción- del término Gewalt: por una parte, significa violencia, pero por otra, Poder, en el sentido del Poder legítimo, autoridad. ${ }^{9}$ Esta ambigüedad es, pues, la que permite establecer una clasificación relativa de la violencia misma: si Gewalt es violencia y Poder (poder autorizado), será violencia en tanto momento de exterioridad del derecho y será Poder en tanto interioridad del Derecho o ejercicio mismo del monopolio de la fuerza por parte de dicho Poder. Así, la cuestión de la Gewalt parece ser una cuestión puramente topológica. Siendo un acto de fuerza la instalación misma del derecho, ${ }^{10}$ de una fuerza realizativa o performativa, que posibilita la institución misma del ámbito jurídico, el origen de lo jurídico mismo no es legal sino que, antes bien, responde a la fuerza misma, a un «poder constituyente» que es la fuerza misma que se itera en el «poder constituido». ${ }^{11}$ Para decirlo en términos benjaminianos, es la iteración de una violencia mítica, que a un tiempo funda, pero a otro conserva: violencia instituyente y conservadora constituyen la dinámica de una misma violencia en el ejercicio de su iteración.

¿Pero qué relación posee este derecho con la justicia? ¿Es la justicia realizable en lo jurídico? Derrida muestra cómo si bien es posible hablar de una justicia que se realiza (o al menos sería posible de realizarse) en el ámbito del derecho, habría que postular otra justicia, una justicia infinita por fuera del derecho y de toda fuerza (enforzability). Esta justicia que se separa en alguna medida del derecho (ya veremos en qué medida), es exigida como una postulación necesaria que se anuncia en las primeras páginas del texto:

Quiero insistir inmediatamente en reservar la posibilidad de una justicia, es decir, de una ley que no sólo excede o contradice el derecho, sino que quizás no contiene ninguna relación con el derecho o que mantiene una relación tan extraña que lo mismo puede exigir el derecho como excluirlo. ${ }^{12}$

Vemos aquí una distinción que se avecina entre, por una parte, un derecho que se impone a partir de su fuerza misma (no de su justicia) y -y esta será la carta fundamental de Derrida- la necesidad de poder, no obstante, postular una justicia que, manteniendo algún tipo de relación con el derecho, no quede

9 J. Derrida 1994d, p. 19 (trad., p. 17).

10 La influencia benjaminiana en estas caracterizaciones resulta más que evidente. En este punto, el paralelo sería con la violencia mítica que instala el derecho. Intentaremos, más adelante pensar la relación entre justicia y violencia divina que destruye el derecho.

11 Y la consecuencia de esta fundación «ilegal» del derecho puede insertarse, como Derrida mismo lo señala, en uno más de los momentos de la violencia del fundamento.

12 J. Derrida 1994d, p. 17 (trad., p. 16). 
sin embargo reducida a éste. Nuestra labor entonces, será elucidar esta relación y, fundamentalmente, intentar pensar una conexión entre ambos términos, conexión que no resulta a simple vista tan evidente, dado el énfasis del filósofo franco-argelino por distinguirlos.

Sin embargo, antes de indagar sobre esta relación veamos otras de las características que son adjudicadas al derecho en esta obra. Además de la dimensión de la aplicabilidad del derecho, en tanto enforzamiento, existen otras notas que Derrida resalta en este texto, estableciendo así la distinción con la justicia de una forma más clara. En este sentido, podemos señalar que todo derecho es derecho positivo, teniendo en cuenta que desde un primer momento, Derrida rechazaría toda concepción de algo que diera en llamarse «derecho natural». ${ }^{13}$ ¿Y cuál es la característica fundamental de todo derecho positivo? Entre otras podríamos mencionar la de su historicidad y, por tanto, su contingencia. ${ }^{14}$ Una vez fundado el derecho, desde una situación que no puede pensarse como legal, se instala la legalidad como el ámbito en el cual el derecho ya fundado otorga legitimidad, pero este sello de origen violento y no fundamentado es la marca misma de su carácter histórico y, por tanto, contingente. Si la violencia funda al derecho, el derecho no es fundado:

Dado que en definitiva el origen de la autoridad, la fundación o el fundamento, la posición de la ley, sólo pueden, por definición, apoyarse en ellos mismos, éstos constituyen en sí mismos una violencia sin fundamento [...] No son legales ni ilegales en su momento fundador, excediendo la oposición entre lo fundado y lo no fundado, entre todo fundacionalismo o antifundacionalismo. ${ }^{15}$

A partir entonces de este carácter histórico del derecho podemos señalar una tercera característica: el derecho es deconstruible:

En la estructura que describo de esta manera, el derecho es esencialmente deconstruible, ya sea porque está fundado, construido sobre capas textuales inter-

13 Una concepción de carácter iusnaturalista presentaría, en principio, las características de un derecho ahistórico y, por tanto, delataría el intento de perpetuación de todo derecho, en tanto fuerza que se instala y luego intenta perpetuarse. Por otra parte, y siguiendo los desarrollos post-nietzscheanos en torno a la pérdida del fundamento, al menos de fundamentos «dados» para el hombre y el pensamiento, parecería extraño considerar la posibilidad de postular un derecho natural, en tanto que dicha concepción de lo jurídico se sostendría de una concepción de la naturaleza humana en términos de sujetos.

14 Recordemos en este punto la caracterización de Benjamin acerca del derecho positivo y su condición deudora, a diferencia del iusnaturalismo de toda historicidad. Para ello ver W. Benjamin 1972.

15 J. Derrida 1994d, p. 24 (trad., p. 34). 
pretables y transformables (y esto es la historia del derecho, la posible y necesaria transformación, o en ocasiones la mejora del derecho), ya sea porque su último fundamento por definición no está fundado. ${ }^{16}$

Esta tercera característica -la deconstructibilidad del derecho- podría ser considerada como una precariedad inherente al derecho mismo: una vez que se han forjado las leyes, el erosionamiento, el desgastamiento de las mismas, a lo único que conducirá es al riesgo de toda interrupción de un estado de derecho, o a la pérdida de la eficacia-aplicabilidad (de la enforzability) de las leyes mismas. Derrida, sin embargo, valora esta característica positivamente: en la medida en que el derecho es deconstruible, puede ser transformado e inclusive mejorado. Quizás la clave para pensar esta valoración positiva sea justamente la posibilidad de contar con una condición siempre abierta cuya apertura sea marcada por su origen mismo, evitando o pudiendo suspender así una acción jurídica de carácter totalitaria. ${ }^{17}$

Para pensar la razonabilidad de este punto, podrá servirnos de analogía la cuestión del «estado de excepción». En Estado de excepción ${ }^{18}$ Giorgio Agamben recoge algunas reflexiones de distintos juristas que habrían tendido a brindar un marco jurídico, una dimensión legal a dicho concepto, cerrando la apertura misma de lo jurídico y otorgando así aun a lo más exterior del derecho, como podría ser un estado de excepción, una dimensión legal. ${ }^{19}$ Nuevamente acer-

16 J. Derrida 1994d, pp. 34-35 (trad., p. 35).

17 Esta es, de hecho, la postura que adopta en J. Derrida 2002, donde defiende la necesidad de postular una manera distinta de pensar el marxismo, enfatizando su espíritu crítico, que pueda desentenderse así de un marxismo que conllevó al Gulag. Ver M. Sprinker (comp.) 2002, especialmente pp. 282-283.

18 G. Agamben 2003, fundamentalmente el cap. I «Estado de excepción como paradigma de gobierno», donde el filósofo italiano releva los desarrollos de juristas europeos del siglo XIX y XX acerca del estatuto del estado de excepción y la posibilidad de brindarle un marco jurídico o no a dicha situación.

19 La analogía con el Estado de excepción -al menos con la tematización schmittiana- llega a su límite en el momento en que el objetivo de tal concepto parece ir en la línea opuesta a la que desde una somera reconstrucción queremos aquí continuar.

Para Schmitt, el Estado de excepción representa la garantía de continuidad de lo jurídico. La «suspensión del derecho» que dicho concepto representa tiene por objeto defender o restaurar (en el modo de la fundación) la constitución vigente y no de deponerla, como parece ser el caso de Benjamin (siguiendo en cierto modo a Sorel) y del Derrida que queremos pensar aquí mismo, aunque, como veremos hacia el final de nuestro artículo, desde un posicionamiento político más moderado.

Para Schmitt -como de un modo más que brillante muestra Agamben-el Estado de excepción es un espacio que, si bien es anómico, pone en juego una fuerza-de-ley sin ley o fuerza-de-łey (G. Agamben 2003, «Fuerza-de-łey»), a través del cual el derecho busca anexarse la propia ano- 
cándose a Benjamin (de un Benjamin soreliano) y alejándose de Schmitt, para Derrida el riesgo más importante es el de no dejar un espacio por fuera de lo jurídico desde el cual poder evitar la tendencia a perpetuarse de algo que, por su naturaleza misma, debería ser finito. ${ }^{20}$ Para Derrida, el carácter histórico del derecho (siempre positivo) abre un espacio, más aun, muestra un espacio desde siempre abierto que posibilita su carácter deconstruible. Y esta condición de deconstructibilidad es la que favorece al derecho, en tanto renovamiento constante de una legalidad entre los hombres que no puede detenerse por su misma condición histórica, condición, por otra parte, que emana de la condición histórica misma de los seres humanos. En la medida en que el derecho es construible, es al mismo tiempo deconstruible. ${ }^{21}$

Ahora bien, a nuestro juicio, el carácter deconstruible del derecho no debe ser considerado como el mero ejercicio subjetivo de reforma o renovación de las leyes sino, antes bien, como un proceso puesto en marcha, ya desde siempre en marcha, que opera en el plano de lo posible desde el ámbito de lo imposible, en el cual hallamos la justicia derridiana.

I.2. Recapitulemos entonces las características del derecho y, desde allí, intentemos elucidar las indicaciones que el filósofo franco-argelino señala acerca de lo que podría ser esta justicia que no se reduce al derecho y que, no obstante, parece mantener una relación extraña con él. Si las notas del derecho son: historicidad, fuerza y deconstructibilidad, además del cálculo, del elemento administrativo que todo lo jurídico en tanto que tal comporta; las características de la justicia no podrán ser las mismas dada su condición heterogénea con respecto al derecho. La primera nota fundamental de la justicia será que ella misma, en tanto tal, no es deconstruible:

mia. Así, frente al «fundamento místico de la autoridad» analizado tanto por Agamben en Estado de excepción, como por Derrida en Fuerza de ley, nos interesará acercarnos, en contraposición, a una noción benjaminiana como la de «violencia mística» que, en tanto violencia revolucionaria, nos permita pensar un espacio de deposición y no de conservación de lo jurídico.

20 En el caso de Benjamin, se puede observar claramente una separación de la posición schmittiana en el momento en que a diferencia de este último, en cuya postulación la decisión se presenta como el vínculo entre soberanía y estado de excepción -como muy bien lo resalta Agamben en «Gigantomaquia en torno a un vacío» (Agamben 2003, p. 108)-Benjamin reemplaza «decidir» por «excluir», expresando así la indecibilidad del soberano como garantía en cierto modo del cumplimiento de la ley. Quizás por ello mismo la octava tesis («La tradición de los oprimidos nos enseña que el estado de excepción en el cual vivimos es la regla», W. Benjamin 1973) de alguna manera haga alusión al lugar en el que Benjamin pensaba del estado de excepción, a saber, en estrecho vínculo con el totalitarismo.

21 J. Derrida 1994d, p. 35 (trad., p. 35). 
La justicia en sí misma, si algo así existe fuera más allá del derecho, no es deconstruible. $^{22}$

Y así como el derecho es el ámbito de lo calculable, la justicia es lo no calculable:

El derecho no es la justicia. El derecho es el elemento del cálculo, y es justo que haya derecho; la justicia es incalculable, exige que se calcule lo incalculable; y las experiencias aporéticas son experiencias tan improbables como necesarias de la justicia. ${ }^{23}$

Todas estas notas nos llevan hacia un mismo camino que desde lejos ya veíamos acercarse: la experiencia de la justicia es la experiencia de lo imposible. Y esta imposibilidad está ligada a su carácter infinito, incondicionado, incalculable, etc., características, todas ellas, que parecen definirse por oposición a lo posible mismo que representa el derecho.

Ahora bien, si la justicia es imposible, ¿cómo podría realizarse en el derecho? ¿Acaso ella indica algún tipo de marco normativo, algún elemento evaluador de la praxis, mediante el cual el derecho pudiera ser valorado o limitado? Como veremos más adelante, la justicia en tanto experiencia de lo imposible no podrá ser pensada como un marco regulativo, ni ofrecerá un criterio de evaluación de la praxis. En otros términos, nunca podremos, a partir de esta caracterización de la justicia, adjudicar el predicado «justo» a un situación, acción o norma, esto es, no existe la posibilidad de decir «X es justo»: ${ }^{24}$

[L]o que se llama la deconstrucción no ha hecho otra cosa que abordar el problema de la justicia, sin que lo haya podido hacer directamente, sino de una manera oblicua. Oblicua como en este momento mismo en el que yo me dispongo a demostrar que no se puede hablar directamente de la justicia, tematizar u objetivar a la justicia, decir «esto es justo» y mucho menos «yo soy justo», sin que se traicione inmediatamente la justicia, cuando no el derecho. ${ }^{25}$

Sin embargo, resta elucidar cuál es esta relación extraña entre la justicia y el derecho ya que, ¿tendría sentido hablar de una justicia completamente exte-

22 Ibíd.

23 J. Derrida 1994d, p. 38 (trad., 39).

24 Más aún, quizás debamos pensar que una de las notas más importantes de la justicia es su carácter anómico, carácter que -como veremos más adelante- se resiste a ser capturado por cualquier nomos y que, por ello mismo, representa cierta garantía de apertura de lo jurídico.

25 J. Derrida 1994d, p. 26 (trad., p. 25). 
rior al derecho? ¿Qué papel ocuparía una justicia imposible frente a un derecho inevitable ${ }^{26}$-posible?

Para ello, quizás lo mejor sea comenzar por abordar el problema de lo imposible, su estatuto, y si existe algo así como una eficacia de lo imposible o, en otros términos, ¿qué rol ocuparía lo imposible en lo posible?

I.3. Uno de los textos donde quizás Derrida tematiza de manera más exhaustiva la problemática de lo imposible es Políticas de la amistad. ${ }^{27}$ Obra consagrada a la cuestión de la amistad, retomando el legado nietzscheano del amigo (del aquel «amor al lejano»), puede considerarse fundamentalmente como un libro dedicado a criticar la idea de democracia heredada de la revolución francesa a partir de la deconstrucción de la idea de fraternidad (de aquel «amor al prójimo» al que Nietzsche aludía en Así habló Zaratustra ${ }^{28}$ ) y el anuncio de una nueva forma de pensar la filosofía, de una filosofía «sin garantías»-quizás podamos decir-, donde el filósofo franco-argelino tematiza la cuestión de lo imposible a partir de la noción «quizás». El vielleicht nietzscheano es retomado por Derrida, en la construcción de una herencia algo extraña, entre pensadores de la filosofía que, desde sus márgenes, habrían socavado de alguna manera esta misma historia. «Quizás» pertenecería, a juicio de Derrida, a un vocabulario exterior a la filosofía, entendida como discurso de la certeza, de la verdad o de la veracidad. ${ }^{29}$ La filosofía derridiana entonces se presenta en este texto como una filosofía del quizás, retomando el legado nietzscheano y contra Heidegger. ${ }^{30}$ En este sentido, Derrida juega con la idea de que esta nueva forma de pensar la filosofía representa una locura. Y esta locura se debe fundamentalmente a la

26 Esta curiosa inevitabilidad del derecho parece estar ligada a la inevitable «positividad» a la que Hegel aludía y que luego Kojève y Agamben retomarán, incluso en su vinculación con la noción -en el caso de este último- de dispositivo. $C f$. G. Agamben 2006.

27 J. Derrida 1994. El origen de este libro, como gran parte de la obra derridiana, fue un seminario dictado entre los años 1988 y 1989 bajo el mismo título.

28 F. Nietzsche 1972. Ver fundamentalmente, «De amigo» $\mathrm{y}$ «Del amor al lejano».

29 J. Derrida 1994c, p. 47 nota al pie $n^{\circ} 1$ (trad., nota. $n^{\circ}$ 6, p. 47). En esa misma nota, Derrida presenta una breve y peculiar etimología del vocablo alemán. Vielleicht derivaría de significaciones como sehr leicht (muy fácil o sencillo), vermutlich (probablemente, verosímilmente) y möglicherweise (posiblemente). Dada esta constelación semántica, el filósofo francés señala que las afirmaciones que se formularían conjuntamente con estos adverbios o modalizadores no se presentarían en principio como enunciados de carácter descriptivo (en tanto enunciados que tienen la característica de ser verdaderos o falsos en su concordancia con «lo que es»), sino como un discurso que no procede ya mediante proposiciones.

30 Para ser más precisos, al menos contra un primer Heidegger, el de El ser y el tiempo, 1952), pero más cercano quizá al Heidegger de Contribuciones a la filosofía. Acerca del evento, 2003), donde el filósofo alemán tematiza la cuestión del acontecimiento, central, a mi juicio en el legado recogido por Derrida y que también nos acercará a la temática de lo imposible. 
introducción de elementos que no serían esperables para una filosofía posible. La filosofía derridiana entonces, en tanto locura, en tanto filosofía del quizás, sería una filosofía de lo imposible. Imposible, porque justamente una filosofía de lo posible sería una filosofía fruto de las condiciones de posibilidad que lo efectivo arroja y, por tanto, una filosofía reproductiva y conservadora, en algún sentido. Nuevamente, posible e imposible aparecen en el escenario estallando la conceptualidad tradicional y exigiendo una articulación inmediata. Sin embargo, antes de trabajar en torno a esta articulación, veamos cuáles son las notas que Derrida asigna a la noción de lo imposible y cuál podría ser el origen de esta noción. Para ello, sería importante observar el origen, cuando no de lo imposible, de la noción de lo posible.

La modalidad de lo posible es retomada a partir de los desarrollos heideggerianos de Ser y tiempo en la analítica existencial, donde el filósofo alemán caracteriza el ser del Dasein. Recordemos que Heidegger atribuye a este ente una modalidad de existencia diferente a la tradicional, pensada en términos de presencia, de un completo y simple estar allí (Vorhandene). Para Heidegger, el Dasein es posibilidad, es sus posibilidades. El Dasein en tanto existencia inacaba$\mathrm{da}$, es tarea que no remite a una esencia específica sino que se va realizando en su mismo existir. La modalidad de la posibilidad propicia, justamente, pensar este tipo de existir que no resulta definido de antemano, certero desde siempre, sino abierto al devenir mismo de la existencia para resolverse en él. Y ese poder-ser (Sein können) que el Dasein es, permite pensar entonces la subjetividad como apertura hacia la posibilidad, dejando atrás las consideraciones de la subjetividad como pura presencia, como una existencia ya desde siempre cerrada y acabada. Porque la existencia precede a la esencia, el Dasein es sus posibilidades, siendo su única posibilidad certera e irrebasable su propia muerte.

Ahora bien, Derrida afirma que lo posible meramente posible, se presenta de antemano ya asegurado, ya dado, como posible sin más. Es por ello que Derrida habla del «triunfo de lo posible sobre lo imposible», sobre lo impensable, lo que no puede ser planeado, sobre lo que efectivamente da lugar al acontecimiento y lo modaliza desde una posibilidad ya establecida:

No puede uno contentarse con las condiciones de posibilidad, la potencialidad incluso de lo que sobreviene «una sola vez», y creer entonces (una cosa así sería bien ingenua) que cabe decir algo pertinente. ${ }^{31}$

Sin embargo, antes de continuar con este análisis y frente al aparente alejamiento de la filosofía derridiana respecto del camino heideggeriano, sería interesante establecer cierta línea de continuidad en la problemática de lo po-

31 J. Derrida 1994d, p. 35 (trad., p. 35). 
sible. Quizás habría que distinguir, en rigor, dos modalidades de lo posible, a saber, una modalidad que se presenta como resultado del proceso reproductivo de lo efectivo y que supone pensar la potencia en una relación de subordinación ontológica del acto -y que, creo, es la noción que Derrida utiliza al referirse a lo posible. Por otra parte, habría que pensar otra modalidad de lo posible, que no mantenga una relación directa con la actualización -y que Agamben analiza a partir de la relación entre la potencia y el acto aristotélicos contenidos en la Metafísica en «Qué significa yo puedo». ${ }^{32}$ Esta última concepción de lo posible es la que, a nuestro juicio, está mentando Heidegger en Ser y tiempo a partir de la temática del «ser para la muerte» (Sein zum Tode) desde el §46, y que Derrida estaría en parte retomando en la temática de lo imposible. Lo posible en ese caso sería una posibilidad que nunca se realiza (nunca se agota) en el acto. ${ }^{33}$ En este segundo sentido, pensar lo imposible (con Derrida) sería pensar radicalmente lo posible.

Es por ello, entonces, por lo que Derrida propone una filosofía del quizá, una filosofía imposible:

Lo que ocurre, y en consecuencia sólo ocurre una vez, la primera y la última, es siempre más u otra cosa que su posibilidad. De ésta puede hablarse hasta el infinito sin que jamás aflore la cosa misma que sobreviene. Puede, pues, que el orden sea otro, puede, y que sólo el acontecimiento que sobreviene permita posteriormente, puede-ser (quizá), pensar aquello que lo habrá hecho posible previamente. ${ }^{34}$

A partir de allí, entonces, Derrida postulará la necesidad de una filosofía del quizás, que albergue en su seno al azar y que se despliegue en una temporalidad que se abra al porvenir, pero no como algo premeditado, planeado de antemano. Más aún, Derrida señalará que el porvenir es algo previo al presente:

El porvenir precede al presente, a la presentación de sí del presente, más viejo que el presente pasado; es así como a la vez se encadena a él mismo desligándose. Se desune, y él desune el sí mismo que seguiría queriendo desunirse en esa desunión. ${ }^{35}$

Porvenir y presente parecen unirse en la des-unión misma respondiendo ambos elementos temporales a una dinámica análogamente aporética a la que

32 G. Agamben 2005.

33 Y, en este sentido, es que se incorporará luego en la filosofía derridiana la temática del mesianismo, mostrando cómo lo efectivo no puede identificarse con lo posible.

34 J. Derrida 1994c, p. 35 (trad., p. 35).

35 J. Derrida 1994c, p. 57 (trad., p. 37). 
describimos entre justicia y derecho. Ahora bien, sin entrar todavía en esta problemática, cabe destacar, no obstante, el propósito derridiano que subyace a esta tesis. Sólo una filosofía que, aún en forma oblicua, pueda dar cuenta de este espacio para el acontecimiento, para el ocurrir de algo inesperado, inclusive inaudible, estará a la altura de los tiempos y podrá, en este sentido, no sólo brindar elementos para comprender nuestros tiempos (que nunca pueden ser agotados por lo posible-efectivo) sino también, abrir el espacio para nuevas formas del pensamiento (y) de lo político. La cuestión de lo imposible, entonces, resulta central para abrir un espacio a nuevos pensamientos que no respondan a las simples condiciones de posibilidad que hoy nos arroja la política tradicional:

Se produce así, efectivamente, algo así como un levantamiento del suelo, y querríamos percibir sus ondas sísmicas, de alguna manera, la figura geológica de una revolución política más discreta pero no menos transformadora que las revoluciones identificadas bajo ese nombre, una revolución, quizá, $d e^{36}$ lo político. ${ }^{37}$

Mientras que un pensamiento de lo imposible puede en su doble función contribuir a comprender nuestros tiempos, así como abrir espacio hacia «nuevas condiciones de posibilidad», un pensamiento de lo posible perdería toda la riqueza de esta apertura, apertura que resulta necesaria para todo acontecimiento. En forma análoga, quizás podemos comprender la necesidad del filósofo franco-argelino de postular entonces una idea de justicia imposible, una justicia irreductible a lo jurídico. Un pensamiento solamente de lo jurídico, sería un pensamiento de lo posible, y, en este sentido, sólo podría representar un programa, el desarrollo de un puro cálculo, «un desplegarse sin acontecimiento» ${ }^{38}$ que se cierra sobre sí mismo perpetuando una y otra vez las mismas posibilidades.

II.1. Espectros de Marx representa una de las obras fundamentales de las últimas reflexiones del pensador franco-argelino. Originalmente, una conferencia que había dictado el 22 y 23 de abril de 1993 como apertura del coloquio «Whiter marxism?» en la Universidad de Riverside, California. Tomando como eje central la pregunta acerca del destino del marxismo en un mundo contemporáneo que postula su completo enterramiento, y justamente contra esta tesis, Derrida propone una manera de la pensar la presencia del marxismo en nuestros días a partir de una figura peculiar, a saber, la del espectro. Derrida describe a

36 Es interesante destacar la relevancia de este subrayado. Un genitivo subjetivo pero al mismo tiempo objetivo: revolución que es en sí política, pero que al mismo tiempo, transforma lo político mismo en tanto tal.

37 J. Derrida 1994c, p. 44 (trad., p. 44).

38 J. Derrida 1994c, p. 46 (trad., p. 46). 
partir de extractos de Hamlet, un presente «out of joint» (fuera de quicio), como condición necesaria para la aparición fantasmática (en este caso, del padre de Hamlet). Una de las primeras condiciones para la aparición del espectro es contar entonces con una temporalidad que se abra en su mismo presentarse:

Mantener unido lo que no se mantiene unido, y la disparidad misma, la misma disparidad-volveremos constantemente a ello como a la espectralidad del espectro-es algo que sólo puede ser pensado en un tiempo de presente dislocado, en la juntura de un tiempo radicalmente dis-yunto, sin conjunción asegurada. No un tiempo de junturas negadas, quebradas, maltratadas, en disfunción, desajustadas, según un dys de oposición negativa y de disyunción dialéctica, sino un tiempo sin juntura asegurada ni conjunción determinable. Lo que vale que aquí se dice del tiempo vale también [...] para la historia [...]: «The time is out of joint», el tiempo está desarticulado, descoyuntado, desencajado, dislocado, el tiempo está trastocado, acosado y trastornado, desquiciado, a la vez que desarreglado y loco. ${ }^{39}$

«Out of joint»: las posibles traducciones nos acercan al espectro poniendo en evidencia la lógica del asedio. Por un lado, «acosado», pero también y mayoritariamente, «desarticulado», «descoyuntado», «desquiciado», «desarreglado» podríamos simplemente decir «dislocado». Y esta dislocación, este desquicio del tiempo, es la apertura a la fantología (discurso acerca del fantasma), es decir, a un más-que-ontología, si pensamos la ontología como el discurso acerca de los modos de ser de lo presente que vienen a la presencia. La ontología se abre a la fantología incorporando la figura del espectro, sin poder, no obstante, decir demasiado de ello. Nuestras categorías han sido pensadas bajo la matriz de una concepción del existir que no puede caracterizar a lo fantasmático. Si la ontología entonces es el discurso de «lo que es», bajo la dicotomía «ser o no ser», quizás tengamos que postular una bipolaridad ${ }^{40}$ entre el ser y el no-ser, una bipolaridad extraña, heterogénea, asimétrica, donde lo fantasmático habitaría instancias intermedias de dicha tensión. Ahora bien, es importante destacar aquí que cada lugar de esta tensión polar parecería estar regido por reglas diferentes

39 J. Derrida 1993, p. 41-42 (trad., p. 31). Transcribimos el texto en francés para que el lector pueda detectar el juego semántico que establece Derrida (los subrayados son nuestros): «Maintenir ensemble ce qui ne tient pas ensemble, et le disparate même, le même disparate, cela ne peut se penser, nous y reviendrons sans cesse comme à la spectralité du spectre, que dans un temps du présent disloqué, à la jointure d'un temps radicalement dis-joint, sans conjonction assurée. Non pas d'un temps aux jointures niées, brisées, maltraitées, dysfonctionnantes, désajustées, selon un dys d'opposition négative et de disjonction dialectique, mais un temps sans jointure assurée ni conjonction déterminables.»

40 La cuestión de la bipolaridad es desarrollada por Agamben en la entrevista a la edición castellana de G. Agamben 2003 y en «Arqueología de una arqueología» (2004). 
o diversas. Es decir -y por estar constituida dicha bipolaridad a partir de polos heterogéneos-, cada lugar, cada punto en la tensión, se constituye heterogéneo al resto de los posibles espacios habitables en dicha tensión. De modo que incluir en una bipolaridad a lo fantasmático no sería reducir su estatuto al de la presencia, sino, antes bien, abrir un espacio para su presentación diferida, de la cual sólo podemos dar cuenta a partir de su eficacia por medio de cierta figuras o metáforas precarias como las del asedio:

La Cosa asedia, por ejemplo, habla y causa, habita las numerosas versiones de ese pasaje, «the time is out of joint», sin residir nunca en ellas, sin confinarse jamás en ellas. ${ }^{41}$

La figura del espectro entonces viene a inaugurar un nuevo espacio de apertura en la ontología que posibilitaría pensar, en el caso del objetivo derridiano de Espectros de Marx, la existencia de un marxismo que, aun cuando no se presente de manera efectiva en los tiempos que corren, pueda estar presente en algún sentido, abriendo la esperanza de un por-venir revolucionario.

II.2. Volvamos ahora a la pregunta pendiente hasta aquí: ¿Cuál es esta relación extraña entre justicia y derecho? Nuestra tesis es la siguiente: la misma operación que Derrida realiza con Marx - con alguno de sus espectros-es la que nosotros podemos intentar pensar con la idea de justicia derridiana. Si el espíritu del marxismo tiene una eficacia es porque habita en las relaciones mismas de producción, en su conflictividad, en los movimientos de lucha, etc. Del mismo modo, la idea de justicia posee una eficacia en el derecho en tanto es inmanente a él. Y justamente porque habita en el derecho no puede pensarse como una suerte de ideal regulativo que tiende una teleología (incluso infinita), en tanto dicho concepción delata una concepción errada del estatuto ontológico mismo de la idea de justicia. Pedirle a la justicia un plan o programa mediante el cual el derecho se realice en sus formas jurídicas es esperar algo absurdo, es esperar que la justicia responda a una lógica de lo posible (pensando además, que lo finito puede realizarse en lo infinito). Pero la justicia pertenece al plano de lo imposible y, por ello, tiene la ventaja de poder rebasar (o, para decirlo con Heidegger «trascender») las condiciones de posibilidad que de hecho parece arrojar lo real (abriendo así nuevas condiciones de posibilidad, imposibles hasta ese momento). No obstante, esta virtud parece trastocar en desventaja en la medida en que no brinda un programa, una metodología, una estrategia de aplicabilidad al derecho.

Pensar que la única relación entre justicia y derecho pueda ser la de regulatividad, significaría pensar el vínculo entre justicia y derecho en el plano de la presencia,

41 J. Derrida 1993, p. 42 (trad., p. 32). 
dejando fuera otras posibilidades de existencia como hemos intentado mostrar a partir de la concepción de espectro. ${ }^{42}$ Ahora bien, considerado desde el plano de la presencia, parecería ser que no hay relación posible entre justicia y derecho, en la medida en que la justicia no parece presentar los elementos necesarios para desarrollar una noción que respondiese al propósito de limitar y postular fines, relegando dicho contacto a una empresa irrealizable, es decir, abandonando la posibilidad misma de dicho vínculo (con la consecuente concepción de la idea de justicia como deudora de una filosofía idealista), postulando un hiato entre justicia y derecho.

Abandonando el intento entonces de pensar a la justicia bajo las mismas exigencias que pensamos al derecho, quizás sería más fructífero pensar que la relación entre lo heterogéneo no puede pensarse ni postularse como la relación entre lo igual. Es entonces en este sentido que siendo justicia y derecho pertenecientes a ámbitos heterogéneos (imposible y posible-efectivo) que podemos iniciar una reflexión en la cual nos encontremos con nuevas formas de articulación entre ambas partes, sin por ello abandonar la pretensión de «cierto materialismo» ${ }^{43}$ de la filosofía de la deconstrucción. Y esta posibilidad se presenta con la figura del espectro, figura que (re) aparecerá una y otra vez en un ejercicio imposible de ser previsto en tanto responde a la lógica del acontecimiento, pero que sólo puede tornarse posible, en tanto inmanente al desarrollo de lo jurídico mismo.

III.1. El objetivo de nuestro trabajo ha sido reflexionar acerca de la relación aporética entre lo jurídico y una idea de justicia infinita, imposible; relación que representa la puesta en contacto de dos modalidades, a saber, la de lo imposible con la de lo posible-efectivo.

Hemos intentado señalar que la dimensión de lo imposible en el caso de la justicia no debe ser pensada como un ámbito completamente separado del plano de lo posible aun cuando no respondan a lógicas similares. La forma de contacto entre estos dos ámbitos es brindada por el concepto de espectro: la justicia habita el derecho en forma espectral, dislocándolo pero desde adentro (un adentro y afuera que no son deslindables o que responden a la modalidad de lo posible-efectivo, resultando lo imposible inmune frente a dichas fronteras).

42 Y del cual hacemos aquí usufructo para pensar la articulación entre justicia y derecho y, por tanto, entre lo posible y lo imposible. Para un desarrollo pormenorizado de la noción de espectro cf: C. De Peretti «El espectro: ça nous regarde» en C. De Peretti (comp.) 2003.

43 Respecto a nuestra manera de entender y defender cierto materialismo de la filosofía derridiana, remitimos al lector a nuestro estudio crítico: «La recepción de Espectros de Marx: Herederos derridianos», estudio crítico de los libros Michael Sprinker (comp.) Demarcaciones Espectrales. En torno a Espectros de Marx de Jacques Derrida y Cristina De Peretti (comp.) Espectrografías, en Instantes y azares, escrituras nietzscheanas (ex Perspectivas nietzscheanas) (en prensa). 
En este sentido, la justicia derridiana representa un movimiento interno a los procesos mismos de producción de lo jurídico:

Por el contrario, el espectro al que se enfrentaban «los poderes de la vieja Europa» sin duda alguna habitaba una forma corpórea, a la que no podríamos decir que preexistiera. Como el fantasma del padre de Hamlet, el espíritu del marxismo, la idea de justicia que define, las esperanzas y las promesas que ofrece hicieron todos su aparición en el mundo ya armados [.... ${ }^{44}$

Pero, ¿cómo podemos dar cuenta de esta situación de asedio por parte de la justicia en el derecho? Dado que no es posible una experiencia de lo imposible, podemos, no obstante, señalar a partir del análisis de los procesos mismos de lo jurídico, una cierta eficacia de la justicia que nos indica el operar fantasmático de la dimensión de lo imposible. Y este operar es el operar de una ley inejecutable, de una ley -como diría Agamben en Il tempo che resta- de la inoperancia, de la desarticulación: la justicia es una ley inejecutable.$^{45}$ La justicia desarticula, socava, disloca el derecho, lo abre hacia un proceso que intenta perpetuarse, demorarse -para decirlo con el Heidegger. Representando así un movimiento de excedencia de lo posible, la justicia desarticula, quebrando la posibilidad de que lo jurídico se presente desde un horizonte totalizador:

Al menos debe hacer que esta presencia solo sea posible a partir del movimiento de cierto desquiciamiento, disyunción o desproporción: en la inadecuación a sî́. ${ }^{46}$

Se hace evidente, en este sentido, el énfasis de la filosofía derridiana de postular, junto con la idea de justicia infinita, un elemento heterogéneo a lo jurídico mismo que, por un lado, le brinde cierta legitimidad pero, al mismo tiempo, lo sostenga en una situación de pura contingencia. Una idea de justicia que mantenga cierta exterioridad (cierta ajenidad o heterogeneidad) con el derecho mismo. ¿Con qué objetivo? Con el objetivo de señalar el estatuto provisorio de todo derecho, su condición histórica. Y esta excedencia sólo puede pensarse, como ya dijimos antes, a partir de instancias intermedias entre el ser y el no ser, instancias en las cuales buscamos a una justicia paradójicamente ilocalizable:

44 J. Derrida 1993, p. 119 (trad., p. 94).

45 Para ello, remito al texto de G. Agamben, 2000. Sería interesante quizás reflexionar, por supuesto nosotros no podremos hacerlo aquí, una idea de justicia como la derridiana con la caracterización de Agamben de un segundo tipo de ley (siendo la primera una ley normativa, nómica) del tipo de la promesa, es decir, una ley sustraída al principio de la obra. Esta temática se halla, por cierto, estrechamente ligada a la cuestión del mesianismo, presente en las reflexiones derridianas de sus últimos años.

46 J. Derrida 1993, p. 16 (trad., p. 13). 
Esta lógica del asedio no sería sola más amplia y más potente que una ontología o que un pensamiento del ser. ${ }^{47}$

III.2. En las primeras páginas de nuestro trabajo hemos establecido cierta filiación entre la caracterización de lo jurídico presente en Fuerza de ley y la violencia mítica benjaminiana desarrollada en Para una crítica de la violencia, como aquella violencia fundadora y (en su iterabilidad) conservadora de lo jurídico. Ahora bien, como sabemos, Benjamin postula en esta misma obra otra figura de la violencia, divina o mística, que tiene por función principal la deposición de todo derecho.

La violencia divina, que oscila entre los términos disolución, interrupción, anarquía y purificación (carácter, por cierto, escatológico), es el espacio que Benjamin delimita para pensar la violencia revolucionaria. La violencia divina interrumpe, corta, el ciclo autorreproductivo de lo jurídico, de un derecho establecido. Los ejemplos fenoménicos desde los que parte esta posibilidad de pensar un tipo de violencia por fuera del derecho, que logre deponer un poder históricamente sancionado, son tres: la figura del gran delincuente, el concepto de huelga revolucionaria soreliana y la guerra. Cada uno de ellos permite en algún sentido mostrar la caducidad de un orden establecido.

Como podemos observar, las características que el autor del Drama barroco alemán le asigna a esta modalidad de violencia resuenan notoriamente con las que aquí hemos delimitado para la justicia derridiana. La violencia divina es escatológica y su función purificadora reside fundamentalmente en la deposición de todo derecho, dando lugar a nuevas configuraciones-fundaciones por parte de la violencia mítica.

Ahora bien, esta función ciertamente extrema que Benjamin le asigna a la violencia divina parece modalizarse en cuanto a sus dosis en lo que a la justicia derridiana respecta. Y esta modalización permite que la deposición pueda ser pensada en términos tales como los de desajuste o dislocación, mediante los cuales, la justicia no solamente podría ser considerada como la interrupción radical en la que Benjamin reflexionaba hacia una descripción de la violencia revolucionaria, sino también en la posibilidad de pensar un habitar subterráneo a lo jurídico mismo como el elemento de su apertura y renovación.

Así, la figura del asedio nos conduce a pensar la articulación entre la justicia y el derecho, como un modo que deja por fuera la posibilidad de fundar desde la justicia un espacio de lo jurídico - cosa que, como ya hemos señalado, parecería conllevarnos hacia la perpetuación de un orden establecido (de un demorarse heideggeriano en el ser, para decirlo con «La sentencia de Anaximandro») o por venir-, pero que permite abrir el espacio hacia nuevas configuraciones de 
lo jurídico, desenmascarando su estatuto de creación humana. Quizás en este sentido puedan ser leídas las siguientes líneas agambenianas:

Abrir un paso hacia la justicia no es la cancelación sino la desactivación y la inoperancia del derecho, es decir, un uso diferente del mismo. ${ }^{48}$

\section{REFERENCIAS BIBLIOGRÁFICAS}

AGAMBEN, G. 2004 : «Arqueología de una arqueología», Introducción a un texto de Enzo Melandri, La linea e il circolo. Studio logico-filosofico sull' analogia, Macerata: Quodilbet.

AGAMBEN, G. 2000: Il tempo che resta, Torino: Bollati Boringhieri.

AGAMBEN, G. 2003: Estado de excepción, trad. Flavia e Ivana Costa. Buenos Aires: Adriana Hidalgo editora.

AGAMBEN, G. 2005: La potenza del pensiero, Vicenza: Neri Pozza Editore.

AGAMBEN, G. 2006: Che cošè un dispositivo? Roma: Nottetempo.

BALCARCE, G. (en prensa) «La recepción de Espectros de Marx: Herederos derridianos», estudio crítico de los libros Michael Sprinker (comp.) Demarcaciones Espectrales. En torno a Espectros de Marx de Jacques Derrida y Cristina De Peretti (comp.) Espectrografías, en Instantes y azares, escrituras nietzscheanas (ex Perspectivas nietzscheanas) (en prensa).

BENJAMIN, W. 1972: Zur Kritik der Gewalt, Gesammelte Schriften, Band 2 und 3. Frankfurt am Main: Suhrkamp Verlag.

BENJAMIN, W. 1973: «Sobre el concepto de historia», Discursos interrumpidos. Trad. Jesús Aguirre. Madrid: Taurus.

CRAGNOLINI, M. B. 2001: 1999: «Derrida: deconstrucción y pensar en las fisuras», Conferencia en la Alianza Francesa, ciclo «El pensamiento francés contemporáneo, su impronta en el siglo», Buenos Aires, 30 de septiembre.

CRAGNOLINI, M. B. 2001: «Para una "melancología" de la alteridad: diseminaciones derrideanas en el pensamiento nietzscheano», publicado en Estudios Nietzsche, Revista de la Sociedad Española de estudios sobre Friedrich Nietzsche, Universidad de Málaga, España, $\mathrm{n}^{\circ}$ 1, pp. 61-76.

CRAGNOLINI, M. B. 2002: «Adagio por la herencia nietzscheana. Herencia recibida y creatividad en el debate deconstruccionismo-hermenéutica», Encuentro Nacional de Fenomenología y Hermenéutica 2002 «Herencia, kairós, creatividad».

CRAGNOLINI, M. B. 2004: «Un mundo de fantasmas y huellas sin origen», publicado en La Nación, Buenos Aires, 17 de octubre..

DE PERETTI, C. (comp.) 2003: Espectrografías. Desde Marx y Derrida, Madrid: Trotta. 
Modalidades espectrales: vínculos entre la justicia...

DERRIDA, J. 1991: «Une “folie” doit veiller sur la pensée», Jacques Derrida. Entrevista con François Ewald en Magazine littéraire consagrada a Jacques Derrida, 286, marzo.

DERRIDA, J. 1993: Spectres de Marx. L'État de la dette, le travail du deuil et la nouvelle Internationale. Paris: Galilée. Versión castellana (1995): Espectros de Marx. El estado de la deuda, el trabajo del duelo y la nueva internacional. Trad. José Miguel Alarcón y Cristina De Peretti. Madrid: Trotta.

DERRIDA, J. 1994a: «Un pensamiento amigo». Entrevista de Robert Magiore con J. Derrida, Libération, 24 de noviembre 1994. Versión castellana en No escribo sin luz artificial. Trad. Rosario Ibañez y Ma. José Pozo. Valladolid: Cuatro, 1999.

DERRIDA, J. 1994b: «La democracia como promesa» entrevista de Elena Fernandez con J. Derrida, Jornal de Letras, Artes e Ideias, 12 de octubre en No escribo sin luz artificial. Trad. Rosario Ibañez y Ma. José Pozo. Valladolid: Cuatro, 1999.

DERRIDA, J. 1994c: Politiques de l'amitié suivi de L'oreille de Heidegger, Paris, Galilée. Versión castellana: Políticas de la amistad seguido de El oído de Heidegger, trad. Patricio Peñalver y Francisco Vidarte, Madrid: Trotta, 1998.

DERRIDA, J. 1994d: Force de loi. Le «Fondement mystique de l'autorité ». Paris: Galilée. Versión castellana: Fuerza de Ley. El fundamento místico de la autoridad. Trad. Adolfo Barberá y Patricio Peñalver Gómez, Madrid: Tecnos, 1997.

DERRIDA, J. 1998: «Hoy en día». Entrevista realizada por Thomas Assteuer, aparecida en versión resumida en Die Zeit, 5 de marzo. Versión castellana en No escribo sin luz artificial. Trad. Rosario Ibañez y Ma. José Pozo. Valladolid: Cuatro, 1999.

DERRIDA, J. 2002: Marx \& sons. Paris : PUF /Galilée.

DERRIDA, J. 2003: Philosophy in a Time of Terror. Dialogues with Jürgen Habermas and Jacques Derrida. Versión castellana (2004): Giovanna Borradori, La filosofía en una época de terror. Diálogos con Jürgen Habermas y Jacques Derrida, trad. Juan José Botero y Luis Eduardo Hoyos, Buenos Aires: Taurus, 2004.

DERRIDA, J. Y ROUDINESCO, E. 2001: De quoi demain..., Paris, Libraire Fayard et Éditions Galilée. Versión castellana: Y mañana qué..., trad. Víctor Goldstein, Buenos Aires: FCE, 2003.

HEIDEGGER, M. 1972: El ser y el tiempo. Trad. José Gaos. México: FCE, $1^{\text {a }}$ ed. 1952.

HEIDEGGER, M. 2003: Contribuciones a la filosofía. Acerca del evento (trad. Dina V. Picoti. Buenos Aires: Biblos.

HEIDEGGER, M. 1995: «La sentencia de Anaximandro» en Caminos del bosque, trad. Helena Cortés y Arturo Leyte, Madrid: Alianza.

NIETZSCHE, F. 2000: Así habló Zaratustra. Trad. Sánchez Pascual. Madrid: Alianza.

SCHMITT, C., 2001: «Teología política I» y «El concepto de lo político» en Carl Schmitt, teólogo de la política. Trad. Héctor Orestes Aguilar. México: FCE.

SPRINKER, M. 2002: (comp.) Demarcaciones espectrales. En torno a Espectros de Marx de Jacques Derrida. Trad. Marta Malo de Molina Boledón, Alberto Riesco Sanz y Raúl Sánchez Cedillo. Madrid: Akal. 
Gabriela Balcarce es profesora y Licenciada en Filosofía por la Universidad de Buenos Aires.

\section{Publicaciones recientes:}

«Modos de darse hospitalarios: Algunas reflexiones sobre el mesianismo derridiano», en Paula Hunziker y Natalia Lerussi (comp.), Filantropía, Misantropía y Apatía, Córdoba: Cuadernos de Nombres, 2007, pp. 167-176. ISBN: 978-987-591-082-9.

«Una promesa de hospitalidad: las multitudes» en Cragnolini, M. B. (Comp.) Modos de lo extraño. Alteridad y subjetividad en el pensamiento postnietzscheano, Buenos Aires: Santiago Arcos editor, 2005, pp. 135-149. ISBN: 987-1240-09-0

Línea de investigación:

Filosofía contemporánea, Metafísica, Filosofía política.

Dirección postal:

La Rioja $10822^{\circ}$, 41, (CP: 1221) Ciudad de Buenos Aires, Argentina.

Dirección electrónica: gbalcarce@yahoo.com.ar 